\title{
Kinetic and thermodynamic effects of moisture content and temperature on the ammonia volatilization of soil fertilized with urea
}

\author{
Lei Tao ${ }^{1}$, Guo Xianghong ${ }^{1}$, Ma Juanjuan ${ }^{1}$, Sun Xihuan ${ }^{1,2^{*}}$, \\ Feng Yang ${ }^{1}$, Wang Hongyu ${ }^{1}$ \\ (1. College of Water Science and Engineering, Taiyuan University of Technology, Taiyuan 030024, China; \\ 2. Jinzhong University, Jinzhong 030600, Shanxi, China)
}

\begin{abstract}
The traditional qualitative analysis of the individual factors on the kinetic and thermodynamic parameters cannot sufficiently reveal the mechanism underlying ammonia volatilization in soil. This study aimed to determine the effects of temperature, moisture content, and their interaction on the kinetic and thermodynamic parameters, which revealed the key control mechanism underlying ammonia volatilization, modified the traditional Arrhenius model, and established a quantitative prediction model of cumulative $\mathrm{NH}_{3}-\mathrm{N}$ loss (CNL). Laboratory culture experiments were conducted under different temperatures $(T)\left(15^{\circ} \mathrm{C}, 20^{\circ} \mathrm{C}, 25^{\circ} \mathrm{C}\right.$ and $\left.35^{\circ} \mathrm{C}\right)$ and moisture contents $(\theta)(60 \%, 80 \%$, and $100 \%$ field capacities). Soil ammonia volatilization was also measured every $2 \mathrm{~d}$. Results showed that the effects of individual factors and their interaction on the values of reaction rate $\left(K_{\mathrm{N}}\right)$, Activation free energy $(\Delta G)$, and activation entropy $(\Delta S)$ followed the descending order of $T>\theta>T \cdot \theta$, whereas those of activation enthalpy $(\Delta H)$ and activation degree $(\lg N)$ followed the descending order of $\theta>T>T \cdot \theta$. The interaction showed significant effect on $K_{\mathrm{N}}$ value and insignificant effect on all the thermodynamic parameters. The effects of water and temperature were mainly observed during the preparatory stage and the most critical transition state stage of the chemical reaction, respectively. Given that $\Delta H>0, \Delta G>0$, and $\Delta S>0$, ammonia volatilization is found to be an endothermic reaction controlled by enthalpy. The new $K_{\mathrm{N}}(T)-2$ model with the determination coefficient $\left(R^{2}\right)$ of 0.999 was more accurate than the traditional Arrhenius model with the $R^{2}$ of 0.936 . The new $\mathrm{NH}_{3}(T, \theta)$ model with the mean absolute percentage error $(M A P E)$ of $4.17 \%$ was more accurate than the traditional $\mathrm{NH}_{3}(T)$ model with the MAPE of $7.11 \%$. These results supplemented the control mechanism underlying ammonia volatilization in soil fertilized with urea and improved the prediction accuracy of CNL.
\end{abstract}

Keywords: soil ammonia volatilization, kinetic parameters, thermodynamic parameters, soil moisture content, urea fertilizer, Arrhenius model, $\mathrm{NH}_{3}(T, \theta)$ model

DOI: $10.25165 / \mathrm{j} . \mathrm{ijabe} .20171006 .3232$

Citation: Lei T, Guo X H, Ma J J, Sun X H, Feng Y, Wang H Y. Kinetic and thermodynamic effects of moisture content and temperature on the ammonia volatilization of soil fertilized with urea. Int J Agric \& Biol Eng, 2017; 10(6): 134-143.

\section{Introduction}

Ammonia volatilization is the most important pathway of $\mathrm{N}$ loss in agroecosystems and accounts for

Received date: 2017-01-27 Accepted date: 2017-08-29

Biographies: Tao Lei, PhD, research interest: soil nitrogen cycle, Email: 1csyt@126.com; Guo Xianghong, PhD, Assistant Professor, research interest: soil nitrogen cycle, Email: 165305052@qq.com; Ma Juanjuan, $\mathrm{PhD}$, Professor, research interest: soil nitrogen cycle, Email: 942547847@qq.com; Feng Yang, Master, research interest: soil nitrogen cycle, Email: 375403483@qq.com; approximately $44.1 \%$ of $\mathrm{N}$ fertilized in certain systems ${ }^{[1]}$. Ammonia volatilization causes direct $\mathrm{N}$ loss and influences global climate and soil acidification ${ }^{[2,3]}$. An official document issued by China's Ministry of

Wang Hongyu, Master, research interest: soil nitrogen cycle, Email: 592805666@qq.com.

*Corresponding author: Sun Xihuan, PhD, Professor, research interest: soil nitrogen cycle. College of Water Science and Engineering, Taiyuan University of Technology, Taiyuan, Shanxi 030024, China. Tel/Fax: +86-351-6111079. Email: suntyut@ 126.com. 
Agriculture in 2015 states that reducing the application rate of urea is an effective way to reduce emissions ${ }^{[4]}$. Producing more food with low application rate of urea requires the efficiency improvement in urea utilization. Temperature and moisture content are the most important factors for soil ammonia volatilization. Further understanding the kinetic and thermodynamic effects of the two factors on ammonia volatilization can help identify the control mechanism underlying ammonia volatilization and achieve the quantitative prediction of $\mathrm{N}$ loss, thereby reducing environmental pollution and improving the efficiency of urea utilization.

Ammonia volatilization is a complex process influenced by numerous factors, such as soil moisture, temperature ${ }^{[5]}$, soil $\mathrm{pH}^{[6]}$, rainfall ${ }^{[7]}$, wind speed ${ }^{[8]}$, and the amount of organic matter solution ${ }^{[9]}$. However, soil moisture content and temperature are the key factors that influence the $\mathrm{N}$ cycle and control ammonia volatilization $^{[5,10]}$ because these two factors significantly influence soil aeration and soil enzymatic activities ${ }^{[11]}$. Kinetics and thermodynamics are important methods for analyzing the complicated mechanism underlying $\mathrm{N}$ transformation reaction. Reaction rate $\left(K_{\mathrm{N}}\right)$, temperature coefficient $\left(Q_{10}\right)$, activation enthalpy $(\Delta H)$, activation free energy $(\Delta G)$, activation entropy $(\Delta S)$, and activation degree $(\lg N)$ are the important indicators of the difficulty degree and rate of chemical reaction. In terms of kinetics, many reports indicate that the cumulative $\mathrm{NH}_{3}-\mathrm{N}$ loss (CNL) can be quantitatively described by Elovich-1 model (Equation (1) $)^{[12-14]}$. The value of $b$ in Elovich-1 model indicates the curvature of CNL curve, but these reports improperly consider $b$ as the reaction rate $\left(K_{\mathrm{N}}\right)^{[12-14]}$. Therefore, these kinetic conclusions about $K_{\mathrm{N}}$ are questionable and thus should be further studied.

$$
C_{t}=a+b \cdot \ln (t)
$$

where, $C_{t}$ is the amount of $\mathrm{CNL}(\mathrm{mg} / \mathrm{kg})$ released at time $t(\mathrm{~d}) ; a$ and $b$ are constants.

Several studies reported about CNL under different moisture contents. In these reports, the moisture content is $30 \%^{[12]}$ and the field capacities $(\theta \mathrm{s})$ is $20 \%^{[13]}$ or between $22 \% \theta \mathrm{s}$ and $74 \% \theta \mathrm{s}^{[14]}$. In general, the plants need to be irrigated when the moisture content is less than $60 \% \theta \mathrm{s}$. After irrigation, the moisture content is close to
$100 \% \theta \mathrm{s}$. These previous reports cannot fully reflect the real agricultural conditions and thus require further study. $\mathrm{Gao}^{[14]}$ showed the individual effect of moisture content and temperature on $Q_{10}, \Delta H$, and $\Delta G$, but the coupled effect of the two factors remains unknown. In addition, $\left(\mathrm{NH}_{4}\right)_{2} \mathrm{SO}_{4}$ and $\left(\mathrm{NH}_{4}\right)_{2} \mathrm{CO}_{3}$ were also used in Gao's study. Urea transformation includes hydrolysis, which is different from that of the other two fertilizers. The thermodynamic study on CNL fertilized with urea should be further studied. Several qualitative studies were conducted about soil ammonia volatilization ${ }^{[5,15,16]}$, but both of the individual and the coupled effects of moisture content and temperature on $\Delta S$ and $\lg N$ remain to be elucidated. Furthermore, the key control mechanism of CNL, entropy control or enthalpy control, was also not identified in previous reports ${ }^{[12-16]}$. This study will help improve understanding of CNL mechanism.

The Elovich-1 model cannot provide a meaningful rate parameter $\left(K_{\mathrm{N}}\right)$. Given the deficiencies of Elovich-1 model, a reliable Elovich-2 model (Equation (2)) proposed by Zhang ${ }^{[17]}$ was used in this study. The value of $K_{\mathrm{N}}$ in Equation (2) is the reaction rate ${ }^{[17]}$. The Elovich-2 model is rarely applied in CNL, which does not consider the effects of temperature and moisture content on $K_{\mathrm{N}}$. Therefore, Equation (2) must be further modified as Equation (3).

$$
\begin{gathered}
C_{t}=(1 / m) \ln \left(K_{N} \cdot m\right)+(1 / m) \ln (t) \\
C_{t}=(1 / m) \ln \left(K_{N}(\theta, T) \cdot m\right)+(1 / m) \ln (t)
\end{gathered}
$$

where, $K_{\mathrm{N}}$ is the reaction rate constant; $K_{\mathrm{N}}(\theta, T)$ is the modification function, which indicates the reaction rate under the coupling of thermodynamic temperature $(T)$ and moisture content $(\theta) ; \quad T$ is thermodynamic temperature, $\mathrm{K} ; \theta$ is moisture content, $\mathrm{mg} / \mathrm{kg} ; m$ is a constant.

Arrhenius equation (Equation (4)) is a classic theory in physical chemistry for describing the linear relationship between the logarithm of $K_{\mathrm{N}}$ and the reciprocal value of $T^{[18]}$. The Arrhenius equation can also be expressed in another form as Equation $(5)^{[19]}$. Previous reports did not find a good linear relationship between $\ln \left(K_{\mathrm{N}}\right)$ and $1 / T$ because of the interference of other factors $^{[20,21]}$. The Arrhenius equation needs to be modified to establish an accurate modification function 
$K_{\mathrm{N}}(\theta, T)$

$$
\begin{gathered}
\ln \left(K_{N}\right)=\ln (A)-\frac{E a}{R \cdot T} \\
\ln \left(K_{N}\right)=a+\frac{b}{T}
\end{gathered}
$$

where, $A$ is the pre-exponential factor; $E a$ is the energy differential, $\mathrm{kJ} / \mathrm{mol} ; \quad R$ is the gas constant $(8.314$ $\mathrm{J} / \mathrm{mol} \cdot \mathrm{K})$.

The present study aims to reveal the key control mechanism underlying CNL, determine the important degrees of temperature, moisture content, and the interaction between the two on the kinetic and thermodynamic parameters, and establish a prediction model of CNL under the coupled effects of moisture content and temperature.

\section{Materials and methods}

\subsection{Soil sampling}

Sandy loam was sampled from the Pomology Institute of the Shanxi Academy of Agricultural Sciences, and the samples were air dried and crushed to pass a 10 mesh sieve. Soil type is sandy loam, and the $\mathrm{pH}$ is 8.84 . The moisture content and field capacity are $21.63 \mathrm{~g} / \mathrm{kg}$ and $217.79 \mathrm{~g} / \mathrm{kg}$, respectively. The $\mathrm{NO}_{3}{ }^{-}-\mathrm{N}$ content and $\mathrm{NH}_{4}{ }^{+}-\mathrm{N}$ content is $4.1 \mathrm{mg} / \mathrm{kg}$ and $5.9 \mathrm{mg} / \mathrm{kg}$, respectively. The $\mathrm{pH}$, field capacity, and moisture content were measured using previous methods ${ }^{[22-24]}$. $\mathrm{NO}_{3}{ }^{-}-\mathrm{N}$ and $\mathrm{NH}_{4}{ }^{+}-\mathrm{N}$ contents were determined using a continuous flow analyzer (AA3, Bran Luebbe, Germany). All chemicals used in the experiments were of analytical reagent grade and obtained from Sinopharm Chemical Reagent Beijing Co., Ltd. (Beijing, China).

\subsection{Treatment}

Exactly $151 \mathrm{~g}$ (oven-dry basis) of soil was added to a series of $500 \mathrm{~mL}$ glass beakers. Half of the beakers were treated with $0.1 \mathrm{~g}$ of $\mathrm{CO}\left(\mathrm{NH}_{2}\right)_{2}$ solution (equal to the rate of $309 \mathrm{mg} \mathrm{N} / \mathrm{kg}$ ). Deionized water was added to the beakers to adjust the moisture content of the soil samples to $\theta_{60}, \theta_{80}$ and $\theta_{100}$ levels $(60 \%, 80 \%$ and $100 \%$ field capacities, respectively). The remaining beakers were treated with three different levels of distilled water as the control. The beakers were incubated at different temperatures $\left(15^{\circ} \mathrm{C}, 20^{\circ} \mathrm{C}, 25^{\circ} \mathrm{C}\right.$ and $\left.35^{\circ} \mathrm{C}\right)$ in the incubators for 1-7 weeks. On the odd days after the start of the experiment, ammonia volatilization was quantified using acid traps. Two sponges $(2 \mathrm{~cm}$ in thickness, $8.5 \mathrm{~cm}$ in diameter) were moistened with $10 \mathrm{~mL}$ phosphate-glycerol solution $(40 \mathrm{~mL}$ of glycerol and $50 \mathrm{~mL}$ of phosphate mixed and diluted into $1000 \mathrm{~mL}$ of deionized water). The lower sponge was placed $3 \mathrm{~cm}$ above the soil surface to trap the ammonia from the soil, whereas the upper sponge was placed on the rim of a beaker to trap the ammonia from the atmosphere. Soil water loss through evaporation was replenished with deionized water, and the sponges were replaced every $2 \mathrm{~d}$. The lower sponge and $100 \mathrm{~mL} \mathrm{KCl}$ solution $(1 \mathrm{~mol} / \mathrm{L})$ were added into the flasks, which were then placed inside a mechanical shaker and oscillated at a frequency of $50 \mathrm{~Hz}$ for $1 \mathrm{~h}$. The $\mathrm{NH}_{4}{ }^{+}-\mathrm{N}$ in the pellucid filtrate was determined using a continuous flow analyzer (AA3, Bran Luebbe, Germany).

\subsection{Calculation of kinetic and thermodynamic parameters}

Based on kinetic theory, an Elovich-2 model (Equation (2)) was used to describe the dynamic process of ammonia volatilization. A regression analysis was conducted using the 1st Opt 7.0 software to calculate the parameters of the models from the experimental data. The thermodynamic parameters mainly include temperature coefficient $Q_{10}, \lg N, E a, \Delta H, \Delta G$ and $\Delta S$. $E a$ can be calculated by Equation (4). Other thermodynamic parameters can be calculated by the following equations:

$$
\begin{gathered}
Q_{10}=K_{T 2} / K_{T 1} \\
\lg N=\lg _{10}(N a \cdot \exp (-E a /(R \cdot T))) \\
\Delta H=E a-R \cdot T \\
\Delta G=R \cdot T \cdot \ln \left((R \cdot T) /\left(N a \cdot h \cdot K_{N}\right)\right) \\
\Delta S=(\Delta H-\Delta G) / T
\end{gathered}
$$

where, $K_{T 2}$ and $K_{T 1}$ are the reaction rate constants under temperatures $T_{2}$ and $T_{1}\left({ }^{\circ} \mathrm{C}\right)\left(T_{2}=T_{1}+10\right)$, respectively; $\mathrm{Na}$ is the Avogadro's constant $\left(6.022 \times 10^{-23} / \mathrm{mol}\right) ; h$ is the Planck's constant $\left(6.626 \times 10^{-34} \mathrm{~J} / \mathrm{S}\right)$.

\subsection{Data analysis and model evaluation}

All data were processed using Microsoft Excel 2013. Statistical analysis was performed with IBM SPSS 
Statistics 19 software, and the figures were plotted with Origin 9.1 software. Statistically significant analyses were conducted using one-way and two-way ANOVA. The establishment of models was performed with the 1stOpt 7.0 software. Model accuracy was evaluated using the determination coefficient $\left(R^{2}\right)$ and the mean absolute percentage error (MAPE), which were calculated as follows:

$$
\begin{gathered}
R^{2}=\sum_{i=1}^{n}\left(C_{i}^{\prime}-\bar{C}\right)^{2} / \sum_{i=1}^{n}\left(C_{i}-\bar{C}\right)^{2} \\
M A P E=\sum_{i=1}^{n}\left(\left|C_{i}-C_{i}^{\prime}\right| / C_{i}\right) / n \times 100 \%
\end{gathered}
$$

where, $C_{i}, C_{i}^{\prime}$, and $\bar{C}$ represent the measured, calculated, and average amounts of ammonia $(\mathrm{mg} / \mathrm{kg})$ that were released at $t(\mathrm{~d})$, respectively; $n$ is the number of evaluated data points.

\section{Results}

\subsection{Characteristics of CNL under different treatments}

Figure 1 shows the CNL values under three different moisture contents. All three conditions, which were significantly increased at the initial stage and stabilized with the increase in reaction time, conformed to the rule of logarithmic function. The starting and ending times of the stage with different stages were nearly similar at $15^{\circ} \mathrm{C}$ (Figure 1a). At other temperature conditions, high moisture content equated to a short rapidly increasing stage and a long stable stage (Figures 1b-1d). The CNL values under the three treatments followed a descending order of $\theta_{60}>\theta_{80}>\theta_{100}$ throughout the entire process. The result showed that $\theta_{100}$ is the best treatment to minimize CNL value with a mean of $13.10 \mathrm{mg} / \mathrm{kg}$, which was only $86.9 \%$ and $75.3 \%$ of $\theta_{80}$ and $\theta_{60}$ treatments, respectively, at $15^{\circ} \mathrm{C}$. Analogously, the results for the two treatments were $87.8 \%$ and $75.5 \%$ at $20^{\circ} \mathrm{C}$ (Figure $1 \mathrm{~b}$ ), $88.9 \%$ and $74.4 \%$ at $25^{\circ} \mathrm{C}$ (Figure 1c), and $72.9 \%$ and $59.4 \%$ at $35^{\circ} \mathrm{C}$ (Figure 1d). An extremely significant $(p<0.01)$ difference at $15^{\circ} \mathrm{C}, 20^{\circ} \mathrm{C}$, $25^{\circ} \mathrm{C}$ and $35^{\circ} \mathrm{C}$ and a remarkable $(p<0.05)$ difference at $35^{\circ} \mathrm{C}$ for the three treatments $\left(\theta_{60}, \theta_{80}\right.$ and $\left.\theta_{100}\right)$ were observed.

Figure 1 also shows that the $\mathrm{CNL}$ values at $15^{\circ} \mathrm{C}$, $20^{\circ} \mathrm{C}$ and $25^{\circ} \mathrm{C}$ are close, with the gap becoming increasingly small over time $(0-15 \mathrm{~d})$. When the temperature increased from $15^{\circ} \mathrm{C}$ to $35^{\circ} \mathrm{C}$, the critical times of the two stages decreased from $20 \mathrm{~d}$ to $5 \mathrm{~d}$ at $100 \%$ field capacities $(\theta \mathrm{s}), 20 \mathrm{~d}$ to $7 \mathrm{~d}$ at $80 \% \theta \mathrm{s}$, and $20 \mathrm{~d}$ to $9 \mathrm{~d}$ at $60 \% \theta \mathrm{s}$. In addition, a high temperature equated to fast ammonia emission rate and short emission. The CNL in the $T_{35}$ treatment was higher than that in the other three treatments. As shown in Figure 1, a high temperature equated to the steep growth curves of CNL and a high initial rate. The growth rates of CNL under different temperature treatments followed a descending order of $T_{35}>T_{25}>T_{20}>T_{15}$ at the same moisture content $(0-15 \mathrm{~d})$. Extremely significant $(p<0.01)$ or significant $(p<0.05)$ differences were observed among the four treatments $\left(T_{15}, T_{20}, T_{25}\right.$ and $\left.T_{35}\right)$, except when the $T_{15}$ and $T_{20}$ treatments and $T_{15}$ and $T_{25}$ treatments were compared. After $15 \mathrm{~d}$, the $\mathrm{CNL}$ at $35^{\circ} \mathrm{C}$ presented a nearly stable trend. The $\mathrm{CNL}$ at $20^{\circ} \mathrm{C}$ and $25^{\circ} \mathrm{C}$ reached a stable trend at the same level, and the $\mathrm{CNL}$ at $15^{\circ} \mathrm{C}$ exhibited a stable growth and later exceeded those in the other three treatments.

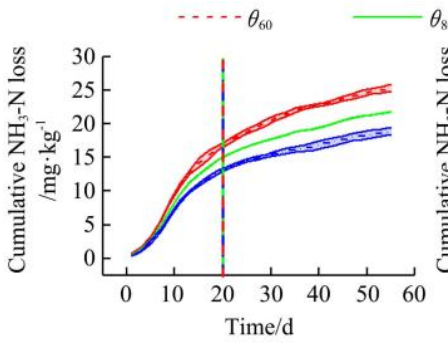

a. $15^{\circ} \mathrm{C}$

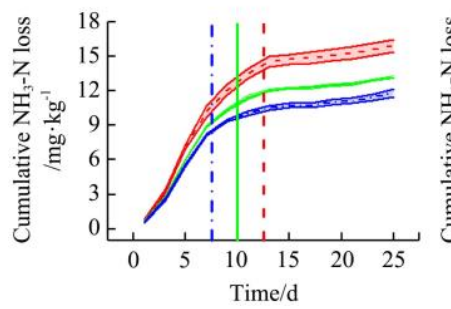

c. $25^{\circ} \mathrm{C}$

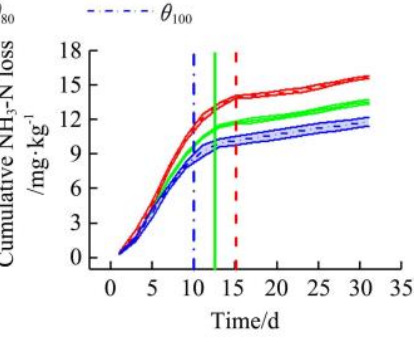

b. $20^{\circ} \mathrm{C}$

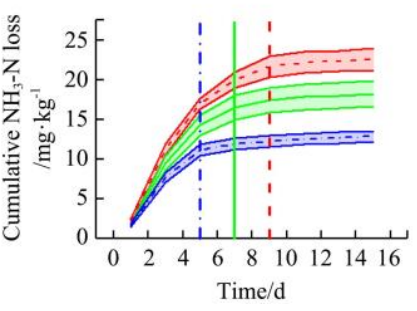

d. $35^{\circ} \mathrm{C}$

Figure 1 Comparison of ammonia volatilization under different moisture content treatment $\left(\theta_{60}, \theta_{80}\right.$ and $\left.\theta_{100}\right)$ at $15^{\circ} \mathrm{C}, 20^{\circ} \mathrm{C}, 25^{\circ} \mathrm{C}$ and $35^{\circ} \mathrm{C}$ (the vertical curve indicated the boundary of the slowly increasing stage and the rapidly increasing stage)

\subsection{Effects of different treatments on kinetic parameters}

The accumulation rate $K_{\mathrm{N}}$ is a key parameter in chemical kinetics and indicates the degree of speed and difficulty of the chemical reaction. The $K_{\mathrm{N}}$ values under 
different temperatures and moisture contents are shown in Figure 2a. The $K_{\mathrm{N}}$ values at different temperature treatments were in the following order: $T_{35}>T_{25}>T_{20}>$ $T_{15}$. The $K_{\mathrm{N}}$ values at $35^{\circ} \mathrm{C}$ were $3.26,3.09$, and 2.98 at $15^{\circ} \mathrm{C}$ at $60 \%, 80 \%$ and $100 \%$ of field capacities, respectively. Figure $2 \mathrm{a}$ indicates that the $K_{\mathrm{N}}$ value decreased with the increasing moisture content. The $K_{\mathrm{N}}$ values under the $\theta_{60}$ treatment were $1.30,1.29,1.28$, and 1.42 higher than those under the $\theta_{100}$ at $15^{\circ} \mathrm{C}, 20^{\circ} \mathrm{C}, 25^{\circ} \mathrm{C}$ and $35^{\circ} \mathrm{C}$, respectively. The maximum and minimum $K_{\mathrm{N}}$ values were found in the areas of low-moisture content and high temperature and high-moisture content and low temperature, respectively. When the moisture content increased from $60 \% \theta$ s to $100 \% \theta$ s, the average change rates of $K_{\mathrm{N}}(\dot{K})$ were $1.304,1.292,1.283$ and 1.424 at $15^{\circ} \mathrm{C}, 20^{\circ} \mathrm{C}, 25^{\circ} \mathrm{C}$ and $35^{\circ} \mathrm{C}$, respectively. When the temperature increased from $15^{\circ} \mathrm{C}$ to $35^{\circ} \mathrm{C}$, the values of average change rates of $K_{\mathrm{N}}(\dot{K})$ were 0.401 , 0.326 , and 0.270 at $60 \% \theta \mathrm{s}, 80 \% \theta \mathrm{s}$, and $100 \% \theta \mathrm{s}$, respectively. This finding indicated the significant difference of $\dot{K}$ under different temperatures and moisture content treatments and thus suggested an interaction between temperature and moisture content during soil ammonia volatilization. The result of two-way ANOVA indicated that the effects of the individual factors and their interaction on the value of $K_{\mathrm{N}}$ followed the descending order of $T>\theta>T \times \theta$ (Table 1). This finding shows the extremely significant effects of moisture, temperature, and their interaction on the value of $K_{\mathrm{N}}$. Therefore, these factors should be considered during the establishment of quantitative models.

\subsection{Effects of different treatments on thermodynamic}

\section{parameters}

The parameters $E a, \Delta H, \Delta G, \Delta S, Q_{10}$, and $\lg N$ are the key factors in thermodynamic theory. Different parameters play a different role in the chemical reaction. The activation energy $(E a)$ is the energy barrier, wherein the reactant molecule transcends in the chemical reaction. The activation enthalpy $(\Delta H)$ is the thermal energy, wherein the reactant molecule is absorbed or released in the chemical process. Activation free energy $(\Delta G)$ is a measurement of free energy, which is needed during

formation and decomposition of the activated complex. $\Delta S$ indicates the probability of achieving the transition state. The analysis of these parameters would reveal the ammonia volatilization mechanism under different temperatures and moisture content.
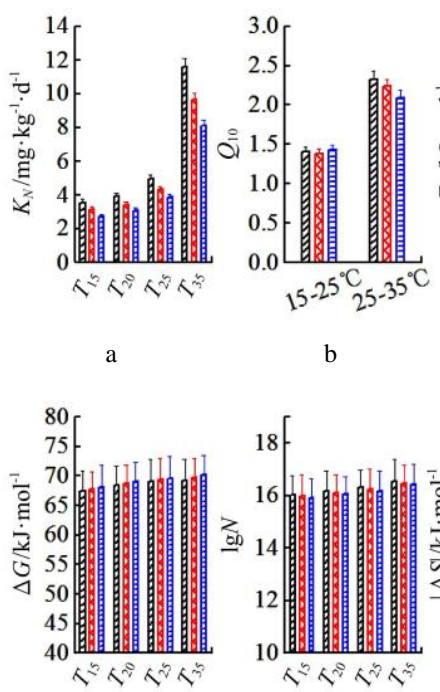

e

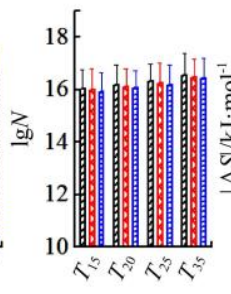

$\mathrm{f}$
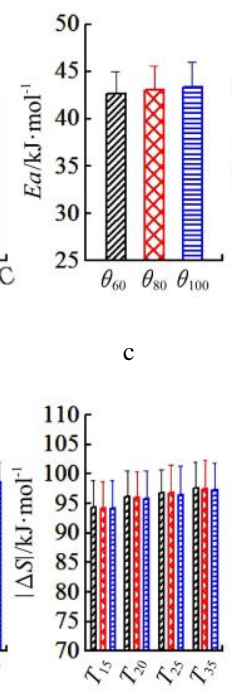

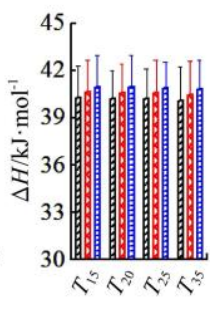

d

Figure 2 Kinetic and thermodynamic parameters of $\mathrm{NH}_{3}$ accumulation under different temperature and moisture content

The thermodynamic parameters under different treatments are shown in Figures $2 \mathrm{~b}-2 \mathrm{~g}$. The $Q_{10}$ values in the high-temperature zone $\left(25^{\circ} \mathrm{C}-35^{\circ} \mathrm{C}\right)$ with averages of $2.322,2.236$ and 2.091 at $60 \%, 80 \%$, and $100 \%$ field capacities, respectively, were 1.47-1.66 times higher than those in the low-temperature zone $\left(15^{\circ} \mathrm{C}-25^{\circ} \mathrm{C}\right)$ (Figure 2b). This finding indicated that the reaction rate $K_{N}$ in the high-temperature zone was more temperaturesensitive than that in the low-temperature zone. $Q_{10}$ with different water treatments and temperature zones was significant $(p<0.01)$. The value of the activation energy $(E a)$, which is the most important thermodynamic parameter, followed a descending order of $\theta_{60}<\theta_{80}<\theta_{100}$ (Figure 3c). The $E a$ difference under different water treatments was extremely significant.

As shown in Figure 2d, when the temperature increased from $15^{\circ} \mathrm{C}$ to $35^{\circ} \mathrm{C}$ or when the moisture content decreased from $100 \% \theta$ s to $60 \% \theta$ s, the activation enthalpy $(\Delta H)$ decreased. This result indicated that the transformation from ammonia to activated ammonia consumed a considerable amount of energy. During the temperature increase, the activation free energy $(\Delta G)$ also 
increased (Figure 2e), but the value of $\Delta G / T$ decreased. This condition promoted reaction. During the increase in moisture content, the accumulation rate of ammonia decreased because of the increase in $\Delta G$ (Figure 2e). The reactant molecules at $35^{\circ} \mathrm{C}$ were easily activated than those at other temperatures. Thus, the activation degree $(\lg N)$ was high (Figure 2f). In addition, when temperature increased or moisture content decreased, the value of $|\Delta S|$ and the molecules with a directional arrangement increased. This condition favored the acceleration of the reaction rate (Figure 2a). The results of two-way ANOVA shown in Table 1 reveal the effects of the interaction. In the two-way ANOVA, temperature significantly or extremely significantly affects $\Delta H(p<0.05), \operatorname{Lg} N(p<0.01), \Delta G(p<0.01)$, and $\Delta S$ values $(p<0.01)$ (Table 1). A significant or extremely significant difference of water treatments was observed on $\Delta H(p<0.05)$ and $\lg N(p<0.01)$ (Table 1). The interaction between temperature and moisture content did not show any effect on the value of the thermodynamic parameters in ammonia accumulation (Table 1). According to thermodynamic theory, the maximal value of $\Delta H$ and the minimal values of $|\Delta S|$ and $K_{\mathrm{N}}$ occurred at $T_{15}$ and $\theta_{100}$ treatments. Therefore, ammonia volatilization is a process controlled by enthalpy.

Table 1 Two-way analysis of thermodynamic parameters under coupling of moisture content and temperature

\begin{tabular}{|c|c|c|c|c|c|c|c|c|}
\hline \multirow{2}{*}{ Treatment } & \multicolumn{2}{|c|}{$\Delta H$} & \multicolumn{2}{|c|}{$\operatorname{Lg} N$} & \multicolumn{2}{|c|}{$\Delta G$} & \multicolumn{2}{|c|}{$\Delta S$} \\
\hline & $\mathrm{F}$ & Sig & $\mathrm{F}$ & Sig & $\mathrm{F}$ & Sig & $\mathrm{F}$ & Sig \\
\hline$T$ & 3.194 & $0.042 *$ & 9.655 & $0.000^{* *}$ & 16.437 & $0.000^{* *}$ & 8.338 & $0.001 * *$ \\
\hline$\theta$ & 5.281 & $0.013 *$ & 13.742 & $0.000 * *$ & 1.147 & 0.335 & 0.468 & 0.825 \\
\hline$T \times \theta$ & 0.310 & 0.925 & 1.009 & 0.443 & 1.137 & 0.371 & 0.079 & 0.925 \\
\hline
\end{tabular}

\subsection{Establishment of kinetic model of CNL}

Arrhenius model is a classic method for studying the chemical reaction kinetics. The $R^{2}$ value of Arrhenius model $\left(K_{\mathrm{N}}(T)\right)$ is within 0.932-0.949. Using this method to analyze the relationship between $\ln \left(K_{\mathrm{N}}\right)$ and $1 / T$ by $K_{\mathrm{N}}(T)$ was reasonable and feasible. However, a new $K_{\mathrm{N}}(T)-2$ model (Equation (13)) (mean $R^{2}=0.999$ ) can better describe the relationship between $\ln \left(K_{\mathrm{N}}\right)$ and $1 / T$ than the traditional $K_{\mathrm{N}}(T)$ model (mean $R^{2}=0.936$ ).

$$
\ln \left(K_{N}\right)=a+b \cdot \exp \left(\frac{c}{T}\right)
$$

where, $c$ is constant.

Moisture content exhibited a significant effect on $K_{\mathrm{N}}$. However, traditional Arrhenius model did not consider the effects of moisture content on $K_{\mathrm{N}}$. The exponential function (Equation (14)) can well describe the relationship between $K_{\mathrm{N}}$ and moisture content (mean $R^{2}=0.997$ ). Given the significant interaction effects of moisture content and temperature on the value of $K_{\mathrm{N}}$, a multiplicative model (Equation (15)) based on Equations (13) and (14) was established. When Equation (15) was combined with Equation (3), kinetic model $\left(\mathrm{NH}_{3}(T, \theta)\right)$ of CNL was obtained. Analogously, when Equation (4) was combined with Equation (2), a traditional kinetic model $\left(\mathrm{NH}_{3}(T)\right)$ of $\mathrm{CNL}$ based on Arrhenius equation was obtained.

$\mathrm{NH}_{3}(T, \theta)$ model was calibrated and validated with $80 \%$ and $20 \%$ data samples, respectively. The best parameters of the $\mathrm{NH}_{3}(T, \theta)$ model are shown in Table 2. Figure 3 shows the linear relationship between the measured and predicted values and the simulation accuracy of the models. As shown in Figure 3a, the slope and $R^{2}$ of the $\mathrm{NH}_{3}(T, \theta)$ model were 1.021 and 0.989 , respectively. The MAPE values of $\mathrm{NH}_{3}(T, \theta)$ model were $4.01 \%$ and $4.17 \%$ with the calibration and prediction samples, respectively (Figure 3b). The simulation accuracy of $\mathrm{NH}_{3}(T, \theta)$ model was compared with that of the traditional model $\left(\mathrm{NH}_{3}(T)\right)$ to show the improvement effect of $\mathrm{NH}_{3}(T, \theta)$. The MAPE values of $\mathrm{NH}_{3}(T)$ model were $6.49 \%$ and $7.11 \%$ with the calibration and prediction samples, respectively (Figure 3c). $\mathrm{NH}_{3}(T, \theta)$ model showed better accuracy than the traditional $\mathrm{NH}_{3}(T)$ model. $\mathrm{NH}_{3}(T, \theta)$ model can be used to describe the process of $\mathrm{CNL}$ under the coupling of moisture content and temperature.

$$
\begin{gathered}
K_{N}=a \cdot \exp (b \cdot \theta) \\
K_{N}(T, \theta)=a \cdot \exp (b+c \cdot \exp (d / T)+e \cdot \theta)
\end{gathered}
$$

where, $d$ and $e$ are constants.

Table 2 Fitting parameters of the $\mathrm{NH}_{3}(T, \theta)$ model

\begin{tabular}{ccccccc}
\hline Model & $\mathrm{a}$ & $\mathrm{b}$ & $\mathrm{c}$ & $\mathrm{d}$ & $\mathrm{e}$ & $\mathrm{m}$ \\
\hline $\mathrm{NH}_{3}(T, \theta)$ & 0.227 & 4.063 & 624440.805 & -462.642 & $-7.889 \mathrm{E}^{-3}$ & 0.171 \\
\hline
\end{tabular}




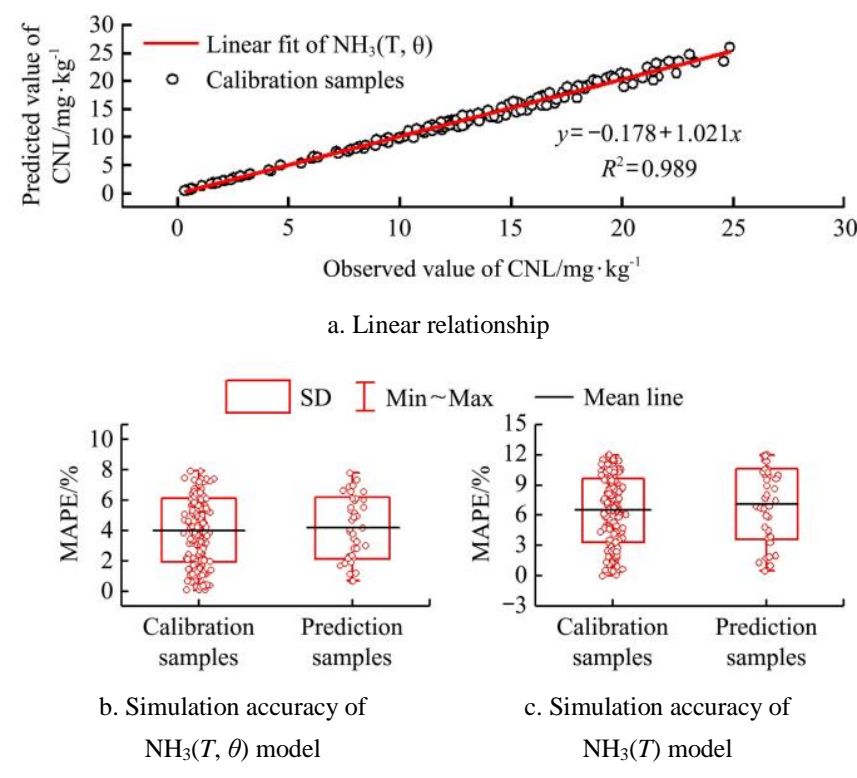

Figure 3 Linear relationship between measured and predicted values, and the simulation accuracy of models

\section{Discussion}

\subsection{Effects of moisture content and temperature on CNL}

Most previous studies suggested that high-soil moisture content is an important environmental factor that leads to high rates of $\mathrm{CNL}$ in applied $\mathrm{N}$ fertilizers ${ }^{[25,26]}$; this finding is different from the results of the current work. In this study, when the moisture content increased from $\theta_{60}$ to $\theta_{100}$ level, the total CNL value decreased by $25 \%$ to $43 \%$. The difference might be due to the different experiment conditions. In previous reports, CNL was determined by the adsorption method using sulfuric acid, and the soil surface is unobstructed. Under this condition, when the soil moisture content increases, the soil evaporation increases and causes the loss of ammonia volatilization ${ }^{[27]}$. In this study, the sponges were placed on the rim of a beaker to trap ammonia, thereby affecting the pathway of water vapor diffusion. The effect mechanism of moisture content on CNL in the previous study is not applicable in the current work.

The negative effect of moisture content on CNL was mainly caused by two reasons. Firstly, urease used is unsaturated in this study, and the hydrolysis rate depends on the substrate concentration ${ }^{[28]}$. When the moisture content decreased from $\theta_{100}$ to $\theta_{60}$, the urease activity decreased by $9 \%$ to $20 \%$, which caused the $\mathrm{NH}_{4}{ }^{+}-\mathrm{N}$ content to increase by $28 \%$ to $58 \%$ (Figure s4). This condition promotes the loss of ammonia volatilization. Secondly, the $\mathrm{pH}$ under $\theta_{60}$ treatment was between 8.32 and 9.16, which was higher than that under $\theta_{100}$ treatment (between 8.19 and 9.07). The amount of $\mathrm{OH}^{-}$under $\theta_{60}$ treatment was between $10^{-5.68} \mathrm{~mol} / \mathrm{L}$ and $10^{-4.84} \mathrm{~mol} / \mathrm{L}$, which was higher than that under $\theta_{100}$ treatment (between $10^{-5.81} \mathrm{~mol} / \mathrm{L}$ and $\left.10^{-4.93} \mathrm{~mol} / \mathrm{L}\right)$. Therefore, the reaction equilibrium with $\theta_{60}$ treatment would shift more easily toward the right side of Equation (16) than that with $\theta_{100}$ treatment.

$$
\mathrm{NH}_{4}^{+}+\mathrm{OH}^{-}=\mathrm{NH}_{3} \uparrow+\mathrm{H}_{2} \mathrm{O}
$$

Previous studies indicated a significant positive correlation between the rate of ammonia volatilization and temperature ${ }^{[29-31]}$. The results of the present study generally support this trend. The urease activity increased by $33 \%-41 \%$ when the temperature increased from $10^{\circ} \mathrm{C}$ to $35^{\circ} \mathrm{C}$. Consequently, urea hydrolysis intensified, thus enhancing $\mathrm{NH}_{4}^{+}$accumulation and solubility. The rate of ammonia diffusion from fluid phase to vapor phase was also accelerated. In conclusion, a high temperature equates to a large amount of ammonia volatilization.

\subsection{Analysis of kinetic and thermochemical mechanisms}

A new kinetic model $\left(\mathrm{NH}_{3}(T, \theta)\right)$ of ammonia volatilization under the coupled effects of moisture content and temperature was established in this study. $\mathrm{NH}_{3}(T, \theta)$ model showed more accurate physical meaning, better prediction accuracy, and more general applicability than the traditional $\mathrm{NH}_{3}(T)$ model. Firstly, the accurate acquisition of $K_{\mathrm{N}}$ is the basis for building a reliable model The value of $b$ in Elovich-1 model indicates the curvature of CNL curve, and some reports consider $b$ as the reaction rate ${ }^{[12,13]}$, which is inaccurate. In the present study, the reaction rate of $K_{\mathrm{N}}$ was determined by using the reliable Elovich-2 model proposed by Zhang et al. ${ }^{[1]}$. The results are more reliable and accurate than those from previous reports. Secondly, when the Elovich-2 and $\mathrm{NH}_{3}(T)$ models were adopted to quantify the CNL, 12 and 4 kinds of models should be established to satisfy the different treatments, respectively. By contrast, one $\mathrm{NH}_{3}(T, \theta)$ model can satisfy all the treatments. $\mathrm{NH}_{3}(T$, 
$\theta$ ) model is more applicable than the other two models. Thirdly, $\mathrm{NH}_{3}(T)$ model and $\mathrm{NH}_{3}(T, \theta)$ model were established based on the Arrhenius equation and $K_{\mathrm{N}}(T)-2$ model, respectively. During modeling, the traditional Arrhenius equation was revised as $K_{\mathrm{N}}(T)-2$ model. The average $R^{2}$ of the new $K_{\mathrm{N}}(T)-2$ model was 0.999 , which was better than that in the Arrhenius equation $\left(R^{2}=0.936\right)$. This result helps improve the model precision of ammonia volatilization. Fourthly, the $M A P E$ value of $\mathrm{NH}_{3}(T, \theta)$ model was $4.17 \%$, which showed better prediction accuracy than the traditional $\mathrm{NH}_{3}(T)$ model (MAPE=7.11\%).

In this study, $Q_{10}$ value was $1.38-1.43$ in the low-temperature zone $\left(15^{\circ} \mathrm{C}-25^{\circ} \mathrm{C}\right)$ and $2.09-2.32$ in the high-temperature zone $\left(25^{\circ} \mathrm{C}-35^{\circ} \mathrm{C}\right)$. The result is different from that of a previous work. $\mathrm{Gao}^{[14]}$ indicated that the $Q_{10}$ values are $1.53-1.74$ at $15^{\circ} \mathrm{C}-25^{\circ} \mathrm{C}$ and $1.39-1.58$ at $20^{\circ} \mathrm{C}-30^{\circ} \mathrm{C}$ when the soil was fertilized with ammonium sulfate $\left(\left(\mathrm{NH}_{4}\right)_{2} \mathrm{SO}_{4}\right)$, whereas the $Q_{10}$ values are 1.49-1.71 and 1.93-2.48 when the soil was fertilized with ammonium carbonate $\left(\left(\mathrm{NH}_{4}\right)_{2} \mathrm{CO}_{3}\right)$. Gao's reports show that a high-temperature zone equates to a low value of $Q_{10}$, whereas the present study shows an opposite trend. The difference might be due to the difference on fertilizer types, soil types, and moisture content level. Firstly, $\left(\mathrm{NH}_{4}\right)_{2} \mathrm{SO}_{4}$ and $\left(\mathrm{NH}_{4}\right)_{2} \mathrm{CO}_{3}$ were used in Gao's reports, whereas urea was used in the current study. The thermostability of urea was different from that of the other two fertilizers. Secondly, the previous proportions of sand, silt, and clay are $25.1 \%, 65.2 \%$, and $9.0 \%$ respectively. By contrast, the present results are $34.6 \%$, $51.5 \%$, and $13.9 \%$ respectively. Therefore, the texture of the two soil samples varied. Thirdly, the moisture content level is between $60 \% \theta$ s and $100 \% \theta \mathrm{s}$ in the current study and is between $22 \% \theta \mathrm{s}$ and $74 \% \theta \mathrm{s}$ in the previous work ${ }^{[14]}$. In general, the plants need to be irrigated when the moisture content is less than $60 \% \theta \mathrm{s}$. After irrigation, the moisture content is close to $100 \%$ field capacities. Therefore, according to these two experimental designs, the current study reflects more real agricultural conditions than the previous reports.

The previous reports showed that the $\mathrm{NH}_{3}$ loss from soils display a decreasing trend with the increasing field capacity and decreasing temperature ${ }^{[32-34]}$. At $15^{\circ} \mathrm{C}-25^{\circ} \mathrm{C}$ and $30 \% \theta \mathrm{s}-70 \% \theta \mathrm{s}$, the interaction between soil moisture and temperature is significant for $\mathrm{NH}_{3}$ loss ${ }^{[35]}$. Although the results of this study supported these trends, a slight deficiency was found in the previous study. The moisture content is usually between $60 \% \theta \mathrm{s}$ and $100 \% \theta \mathrm{s}$ in the agricultural system. The temperature level in Yan's report is lower than that in the real agricultural condition ${ }^{[35]}$. As shown in the experimental methods, the current study reflects more real agricultural conditions than previous reports.

The average values of $E a, \Delta H$, and $\Delta G$ were $47.6 \mathrm{~kJ} / \mathrm{mol}, 45.1 \mathrm{~kJ} / \mathrm{mol}$, and $104.1 \mathrm{~kJ} / \mathrm{mol}$ with $\left(\mathrm{NH}_{4}\right)_{2} \mathrm{SO}_{4}$, whereas $48.7 \mathrm{~kJ} / \mathrm{mol}, 46.2 \mathrm{~kJ} / \mathrm{mol}$, and $105.8 \mathrm{~kJ} / \mathrm{mol}$ with $\left(\mathrm{NH}_{4}\right)_{2} \mathrm{CO}_{3}$ in Gao's report and $34.5 \mathrm{~kJ} / \mathrm{mol}, 40.6 \mathrm{~kJ} / \mathrm{mol}$, and $68.9 \mathrm{~kJ} / \mathrm{mol}$ in this study, respectively ${ }^{[14]}$. The difference might be mainly due to the difference on the chemical properties of the three fertilizers. Although the fertilizer type used in Gao's report is different from those in the current study, the previous result is still important for revealing the effects of temperature and moisture content on ammonia volatilization. Given the inadequacies of the previous report, this study performed a complementary research. Firstly, the coupled effects of the two factors on kinetic and thermodynamic parameters remains unknown in the previous reports. In the current study, the result shows that the interaction between the two factors exhibited a significant effect on the kinetic parameters and an insignificant effect on the thermodynamic parameters. Secondly, the relevant parameters were obtained in the previous report, but the key control mechanism of ammonia volatilization remains to be clarified. The urea concentration under $\theta_{100}$ treatment was $1.42 \mathrm{mg} / \mathrm{mL}$. The substrate concentration increased by $20 \%$ when the moisture content increased to $\theta_{100}$. When the temperature increased from $15^{\circ} \mathrm{C}$ to $35^{\circ} \mathrm{C}$, the $\lg N$ of solute molecules increased by 0.51 unit. On the one hand, these two points help increase the amount of $\mathrm{NH}_{4}{ }^{+}-\mathrm{N}$, thereby accelerating the right moving of chemical equilibrium (Equation (16)). On the other hand, these two points also help increase the percentage of activated molecules and collision efficiency, thereby 
increasing the probability of a chemical reaction and reducing the reaction rate. In addition, under $T_{35}$ and $\theta_{60}$ treatments, $\Delta H$ value was a minimum of $40.1 \mathrm{~kJ} / \mathrm{mol}$. Simultaneously, $|\Delta S|$ and $K_{\mathrm{N}}$ were in a maximum of $97.7 / \mathrm{mol}$ and $11.6 \mathrm{mg} / \mathrm{kg} \cdot \mathrm{d}$, respectively. Therefore, ammonia volatilization is a process controlled by enthalpy according to thermodynamic theory. In conclusion, this study identified the control mechanism of ammonia volatilization in soil fertilized with urea and improved the prediction accuracy of CNL.

\section{Conclusions}

(1) The effects of the individual factors and the interaction on the value of $K_{\mathrm{N}}, \Delta G$, and $\Delta S$ followed the descending order of $T>\theta>T \cdot \theta$, whereas that of $\Delta H$ and $\lg N$ followed the descending order of $\theta>T>T \cdot \theta$. The interaction showed a significant effect on $K_{\mathrm{N}}$ and an insignificant effect in all thermodynamic parameters. The roles of water and temperature were mainly observed in the preparatory stage and the most critical transition state stage of the chemical reaction, respectively. These new findings determined the key and specific role of the two factors during ammonia volatilization.

(2) Given that $\Delta H>0, \Delta G>0$ and $\Delta S<0$, ammonia volatilization is an endothermic reaction controlled by enthalpy. The results represent an important stepping stone toward good understanding of the key control mechanism.

(3) The new $K_{\mathrm{N}}(T)-2$ model with $R^{2}$ of 0.999 was more accurate than the traditional Arrhenius model with $R^{2}$ of 0.936 . The new $\mathrm{NH}_{3}(T, \theta)$ model with the $M A P E$ of $4.17 \%$ was more accurate than the traditional $\mathrm{NH}_{3}(T)$ model with MAPE of $7.11 \%$. The development of these two models represents an important stepping stone toward good understanding of the relationship between $K_{\mathrm{N}}$ and temperature and the relationship between CNL and environmental factors. Therefore, this study provides a valuable tool for predicting ammonia volatilization loss.

\section{Acknowledgements}

This study is supported by the National Natural Science Foundation of China (No. 51579168, 51249002), the Natural Science Foundation of Shanxi Province of
China (No. 201601D011053), the Graduate Education Innovation Program of Shanxi Province of China (No. 2016BY064), the Scientific and Technological Project of Shanxi Province of China (No. 20140311016-6).

\section{[References]}

[1] Zhao Z P, Yan S, Liu F, Ji P H, Wang X Y, Tong Y A. Effects of chemical fertilizer combined with organic manure on Fuji apple quality, yield and soil fertility in apple orchard on the Loess Plateau of China. Int J Agric \& Biol Eng, 2014; 7(2): 45-55.

[2] Zhao Z P, Duan M, Yan S, Liu Z F, Wang Q, Fu J, et al. Effects of different fertilizations on fruit quality, yield and soil fertility in field-grown kiwifruit orchard. Int J Agric \& Biol Eng, 2017; 10(2): 162-171.

[3] Wang L L, Li W Z, Wang Z J, Wang Z W, Sui C, Li Y. Effects of digestate application depth on soil nitrogen volatilization and vertical distribution. Int J Agric \& Biol Eng, 2016; 9: 101-107.

[4] Dou Y, Deng Y J, Cheng S. China's agricultural environmental pollution present situation and the technological innovation path. Scientific Management Research, 2016; 4: 76-79. (in Chinese)

[5] Rochette P, Angers D A, Chantigny M H, Gasser M O, MacDonald J D, Pelster D E, Bertrand N. NH3 volatilization, soil concentration and soil $\mathrm{pH}$ following subsurface banding of urea at increasing rates. Canadian Journal of Soil Science, 2013; 93: 261-268.

[6] Hafner S D, Meisinger J J, Mulbry W, Ingram S K. A pH-based method for measuring gaseous ammonia. Nutrient Cycling in Agroecosystems, 2012; 92: 195-205.

[7] Kissel D E, Cabrera M L, Vaio N, Craig J R, Rema J A, Morris L A. Rainfall timing and ammonia loss from urea in a loblolly pine plantation. Soil Science Society of America Journal, 2004; 68: 1744-1750.

[8] Gong W, Zhang Y, Huang X, Luan S. High-resolution measurement of ammonia emissions from fertilization of vegetable and rice crops in the Pearl River Delta Region, China. Atmospheric Environment, 2013; 65: 1-10.

[9] Rochette P, Angers D A, Chantigny M H, MacDonald J D, Gasser M-O, Bertrand N. Reducing ammonia volatilization in a no-till soil by incorporating urea and pig slurry in shallow bands. Nutrient Cycling in Agroecosystems, 2009; 84: 71-80.

[10] Roelle P A, Aneja V P. Modeling of ammonia emissions from soils. Environmental Engineering Science, 2005; 22: 58-72.

[11] Matsushima M, Lim S S, Kwak J H, Park H J, Lee S I, Lee D 
S, Choi W J. Interactive effects of synthetic nitrogen fertilizer and composted manure on ammonia volatilization from soils. Plant and Soil, 2009; 325: 187-196.

[12] Ji R, Zhu Y, Zhang A, Zhang X. Study on the nitrogen release law of bamboo charcoal coated urea and its biological utilization effects. Agricultural Science \& Technology, 2007; 8: 53-58.

[13] Hu X, Wang Z, You Y, Li J. Ammonia volatilization of slow release compound fertilizer in different soils water conditions. Environmental science, 2010; 31: 1937-1943. (in Chinese)

[14] Gao P C. Study on effects of interaction and model and character coefficients of water and temperature in soil-crop systems. PhD dissertation, Xianyang: University of Northwest Agriculture \& Forestry, 2002. (in Chinese)

[15] Holcomb J C, Sullivan D M, Horneck D A, Clough G H. Effect of irrigation rate on ammonia volatilization. Soil Science Society of America Journal, 2011; 75: 2341-2347.

[16] Fox T R, Jokela E J, Allen H L. The development of pine plantation silviculture in the southern United States. Journal of Forestry, 2007; 105: 337-347.

[17] Zhang Z Q, Meng Z F, Zhang Y P. Recognition of elovich equation. Chinese Journal of Soil Science, 2000; 31: 208-209 (212). (in Chinese)

[18] Moyo C C, Kissel D E, Cabrera M L. Temperature effects on soil urease activity. Soil Biology \& Biochemistry, 1989; 21: 935-938.

[19] Todd R W, Cole N A, Waldrip H, Aiken R M. Arrhenius equation for modeling feedyard ammonia emissions using temperature and diet crude protein. Journal of Environmental Quality, 2013; 42: 666-671.

[20] Vourlitis G L, DeFotis C, Kristan W. Effects of soil water content, temperature and experimental nitrogen deposition on nitric oxide (NO) efflux from semiarid shrubland soil. Journal of Arid Environments, 2015; 117: 67-74.

[21] Frøseth R B, Bleken M A. Effect of low temperature and soil type on the decomposition rate of soil organic carbon and clover leaves, and related priming effect. Soil Biology and Biochemistry, 2015; 80: 156-166.

[22] Li Q, Wen H, HU C. Difference between international and domestic methods in determining soil pH. Soils, 2007; 39: 488-491. (in Chinese)

[23] Aksakal E L, Angin I, Oztas T. Effects of diatomite on soil physical properties. Catena, 2012; 88: 1-5.
[24] Lei T, Sun X H, Guo X H, Ma J J. Quantifying the relative importance of soil moisture, nitrogen, and temperature on the urea hydrolysis rate. Soil Science and Plant Nutrition, 2017 63: 225-232.

[25] Sommer S G, Schjoerring J K, Denmead O T. Ammonia emission from mineral fertilizers and fertilized crops. Advances in Agronomy, 2004; 82: 557-622.

[26] Scivittaro W B, Gonçalves D R N, Vale M L C D, Ricordi V G. Perdas de nitrogênio por volatilização de amônia e resposta do arroz irrigado à aplicação de ureia tratada com o inibidor de urease NBPT. Ciência Rural, 2010; 40: 1283-1289. (in Portuguese)

[27] Chao T, Kroontje W. Relationships between ammonia volatilization, ammonia concentration and water evaporation. Soil Science Society of America Journal, 1964; 28: 393-395.

[28] Stryer L. Biochemistry 4th Ed. New York: Freeman \& Co. 1995.

[29] Fan X H, Li Y C, Alva A K. Effects of temperature and soil type on ammonia volatilization from slow-release nitrogen fertilizers. Communications in Soil Science and Plant Analysis, 2011; 42: 1111-1122.

[30] Cai G X, Chen D L, Ding H, Pacholski A, Fan X H, Zhu Z L. Nitrogen losses from fertilizers applied to maize, wheat and rice in the North China Plain. Nutrient Cycling in Agroecosystems, 2002; 63: 187-195.

[31] Yan L, Zhang Z D, Chen Y, Gao Q, Lu W X, Abdelrahman A M. Effect of water and temperature on ammonia volatilization of maize straw returning. Toxicological and Environmental Chemistry, 2016; 98: 638-647.

[32] He Z, Alva A, Calvert D, Banks D. Ammonia volatilization from different fertilizer sources and effects of temperature and soil pH. Soil Science, 1999; 164: 750-758.

[33] Fan X, Li Y, Alva A. Effects of temperature and soil type on ammonia volatilization from slow-release nitrogen fertilizers. Communications in Soil Science and Plant Analysis, 2011; 42: 1111-1122.

[34] Liu G D, Li Y C. Alva A K. Moisture quotients for ammonia volatilization from four soils in potato production regions. Water, Air, and Soil Pollution, 2007; 183: $115-127$.

[35] Yan L, Zhang Z, Chen Y, Gao Q, Lu W, Abdelrahman A M. Effect of water and temperature on ammonia volatilization of maize straw returning. Toxicological and Environmental Chemistry, 2016; 98: 1-10. 